\title{
Reducing the Global Burden of Work Disability: A Call to Action to Support the World Health Organization's Rehabilitation 2030
}

\author{
Michael Feuerstein ${ }^{1} \cdot$ Patricia A. Findley ${ }^{2} \cdot$ Douglas P. Gross $^{3}{ }^{3}$
}

Published online: 11 October 2019

(c) Springer Science+Business Media, LLC, part of Springer Nature 2019

\begin{abstract}
In July 2019, the Journal of Occupational Rehabilitation participated in the 2nd World Health Organization (WHO): Rehabilitation 2030 meeting held at its headquarters in Geneva, Switzerland. The meeting highlighted the global need for rehabilitation services and research as well as improved access to rehabilitation in primary care for a range of disabling chronic and recurrent conditions. The Journal of Occupational Rehabilitation strongly supports the WHO's well-developed and impressively implemented global effort. A collaborative, interdisciplinary effort is needed to establish and strengthen networks and partnerships between low-, middle- and high-income countries focused on research and management of work disability.
\end{abstract}

Keywords Rehabilitation · Work disability $\cdot$ Global health $\cdot$ International cooperation

In July 2019, the Journal of Occupational Rehabilitation participated in the 2nd World Health Organization (WHO): Rehabilitation 2030 meeting held at its headquarters in Geneva, Switzerland [1]. The international meeting brought together government agencies, researchers, WHO and other United Nation agencies, organizations representing rehabilitation service user groups and rehabilitation providers, funding bodies, major professional organizations, research institutions, journal editors, and relevant international and nongovernmental organizations. The focus of this meeting was furthering the Rehabilitation 2030 Call for Action [2] and operationalization of rehabilitation services and research in the broad area of rehabilitation across the globe [3]. The meeting highlighted the global need for rehabilitation services and research as well as improved access

Michael Feuerstein-Founder and Editor in Chief, Journal of Occupational Rehabilitation.

Douglas P. Gross

dgross@ualberta.ca

1 Neurooncology Branch, National Institutes of Health, Bethesda, MD, USA

2 Rutgers School of Social Work, The State University of New Jersey, New Brunswick, NJ 08901, USA

3 Department of Physical Therapy, University of Alberta, Edmonton, AB T6G 2G4, Canada to rehabilitation in primary care for a range of disabling chronic and recurrent conditions.

The 2019 meeting had a heightened emphasis on the increasing global burden of disability (including work disability) and population health data indicating the need to extend rehabilitation services [4]. Although there was emphasis on the global need for rehabilitation services and research of all types and in all populations, there is a particularly critical need for such services in low- and middle-income countries. The role of an ageing population and rising prevalence of noncommunicable diseases were emphasized, as well as the very limited rehabilitation resources available in terms of providers and funds for delivery of rehabilitation services. Consensus was that the major challenges of an aging global population and associated disabling chronic conditions will add to unpreceded needs for rehabilitation services. Work and economic productivity are functional outcomes of major interest and reducing the global burden of work disability is a key objective.

The Journal of Occupational Rehabilitation strongly supports the WHO's well-developed and impressively implemented global effort [2]. Much still needs to be done to maximize the goals of this Call for Action. We are asking you to respond as practitioners and researchers focused on work disability. A collaborative, interdisciplinary effort is needed to establish and strengthen networks and partnerships between low-, middle- and high-income countries 
focused on research and management of work disability [5]. This world-wide public health initiative can benefit from culture and context-specific efforts to implement interventions known to be effective for reducing work disability, as well as new work disability prevention research to meet the unique challenges of low- and middle-income countries. Perhaps theories and techniques developed for the prevention and management of work disability related to persistent or recurrent conditions in higher income countries that have been the mainstay of this journal for decades can be adapted to meet the needs of work disability in low- and middleincome countries. However, caution will be needed to avoid repeating the problems now faced in high-income countries (i.e., over utilization of surgical and medical interventions, opioid epidemic, etc.) and exacerbating the problem in other areas. However, while types of work and availability of resources vary, applying the theories, methodologies and effective interdisciplinary applications developed over the years may greatly benefit these countries. To help make this happen, we suggest that interested researchers and clinicians contact the WHO Rehabilitation Program at rehabilitation@ who.int and ask for additional information on Rehabilitation 2030. Mention that you are interested in collaboration related to work disability and rehabilitation.

Thank you for any attention and support you can offer. This journal is committed to this global effort as it relates to work disability and will give priority to quality submissions that help facilitate research and practice related to the effort.

\section{Sincerely}

Michael Feuerstein, Ph.D., MPH

Founder and Editor in Chief
Patricia A. Findley, DrPH, MSW

Senior Associate Editor

Douglas P. Gross, Ph.D., BScPT

Senior Associate Editor

\section{References}

1. Report of the Second Global Rehabilitation 2030 Meeting. World Health Organization. 2019. https://www.who.int/news-room/event s/detail/2019/07/08/default-calendar/second-global-rehabilitation2030-meeting. Accessed 30 Aug 2019.

2. Rehabilitation 2030: a call for action. World Health Organization. 2017. https://www.who.int/disabilities/care/Rehab2030M eetingReport_plain_text_version.pdf. Accessed 30 Aug 2019.

3. Rehabilitation in health systems: guide for action. World Health Organization. 2019. https://www.who.int/rehabilitation/rehabilita tion-guide-for-action/en/. Accessed 30 Aug 2019.

4. Second Global Rehabilitation 2030 Meeting Website-Rehabilitation 2030. World Health Organization. 2019. https://www.who. int/rehabilitation/rehab-2030-2nd-meeting/en/. Accessed 30 Aug 2019.

5. Framework for Action on Interprofessional Education \& Collaborative Practice (WHO/HRH/HPN/10.3). Geneva, Switzerland: Health Professions Networks Nursing and Midwifery Human Resources for Health within the Department of Human Resources for Health. 2010. https://www.who.int/hrh/resources/framework_ action/en/. Accessed 30 Aug 2019.

Publisher's Note Springer Nature remains neutral with regard to jurisdictional claims in published maps and institutional affiliations. 